\title{
Determining the Spiritual Care Requirements and Death Anxiety Levels of Patients Diagnosed with COVID-19 in Turkey
}

\section{Seda Şahan ${ }^{1}$ D $\cdot$ Ayşegül Yıldız}

Accepted: 30 October 2021 / Published online: 13 November 2021

(c) The Author(s), under exclusive licence to Springer Science+Business Media, LLC, part of Springer Nature 2021

\begin{abstract}
Our study was conducted to determine the spiritual care needs and death anxiety levels of individuals diagnosed with COVID-19. The population consisted of patients who were diagnosed with COVID-19 in Turkey. The mean total Spiritual Care Requirements Scale score of the participants was 67.05 \pm 26.30 . The mean VAS for Death Anxiety score of the participants was $8.82 \pm 1.26$. In our study, it was found that the patients diagnosed with COVID-19 had an increased need for spiritual care and high levels of anxiety about death.
\end{abstract}

Keywords COVID-19 $\cdot$ Spiritual care $\cdot$ Death anxiety $\cdot$ Nursing

\section{Introduction}

The novel coronavirus disease (COVID-19) which started in December 2019 in Wuhan in China has affected the entire world (Adhikari et al., 2020). COVID-19 has a very fast spreading rate, and numerous countries have been affected by this disease. For this reason, the World Health Organization declared that the novel coronavirus (2019-nCoV) epidemic is an internationally concerning public health emergency (Mahase, 2020). On March 11, 2020, the World Health Organization declared

Our article about Patients Diagnosed with COVID-19 and spiritual care. That's why we think our article is suitable for a Special Section of the Journal. There are no studies on this subject. We want to announce the importance of the subject through your journal.

Seda Şahan

seda.sahan@bakircay.edu.tr

Ayşegül Yıldız

aysegul.yildiz@kapadokya.edu.tr

1 Department of Nursing Fundamentals, Faculty of Health Sciences, İzmir Bakırcay University, Menemen, İzmir, Turkey

2 Dialysis Department, Cappadocia Vocational School, Ürgüp, Nevşehir, Turkey 
COVID-19 as a pandemic. Since the start of the pandemic, approximately 25 million cases and 800,000 deaths have been reported by WHO (WHO COVID-2019 situation reports 209). While COVID-19 progresses asymptomatically or mildly in some patient groups, it may have a severe course ranging from acute respiratory arrest requiring patients to receive treatment in intensive care conditions to death (Mahase, 2020). The uncertainties regarding the course of COVID-19, treatment and vaccination lead to fear, anxiety and depression in people. To reduce these negative effects of COVID-19 on people, it is needed to meet their spiritual requirements. In exceptional cases like a pandemic, the existence of the pandemic or people getting infected increases their spiritual needs (Heidari et al., 2020).

Spirituality, which is confused with concepts such as religion, belief and morale, is a subjective concept that is used with various meanings (Arslan \& Konuk Şener, 2009; Seddigh et al., 2016). Spirituality, which has a search for the meaning and purpose of life in its center (Como, 2007; Selman et al., 2011), is also the effort of the individual to understand themselves, their relationships with other individuals and their place in the universe (Çetinkaya et al., 2007; Selman et al., 2011). From birth onward, every person has a spiritual aspect. The spiritual aspect of people is considered as important as their physical, emotional and social aspects (Como, 2007; Seddigh et al., 2016). Therefore, every individual has spiritual needs that will support their spiritual aspect (Arslan \& Konuk Şener, 2009; Çınar \& Eti Aslan, 2017). Spiritual needs are met through spiritual practices (Como, 2007). Spiritual practices allow the individual to be aware of their spirituality by supporting their positive lifestyle, have increased personal satisfaction, reduced anxiety and be hopeful, strong and in peace. For this reason, it is stated that spiritual practices have positive effects on health and illness (Como, 2007; Deal \& Grassley, 2012; Elham et al., 2015; Lundberg \& Kerdonfag, 2010). In cases of diseases that require long-term treatment and situations that reduce the quality of life, in addition to the physical, emotional, mental and social needs of individuals, their spiritual needs also increase. Spiritual needs are more abstract and complex than physical needs, and they are also difficult to measure. For this reason, in the healthcare of the individual, physical requirements are prioritized, and spiritual requirements may be neglected (Benito et al., 2014; Tiew et al., 2013). However, the holistic nursing approach emphasizes the necessity to not neglect spiritual care (Brennan, 2013). Spiritual care allows individuals to understand the meaning of life, have internal peace, overcome diseases, develop coping strategies that will help them overcome crises, make plans for the future and speed up their healing process (Como, 2007; Lundberg \& Kerdonfag, 2010; Seddigh et al., 2016). Meeting the spiritual needs of individuals during the pandemic process will reduce the anxiety and concerns of people and increase their levels of hope (Heidari et al., 2020). Alongside concerns, the pandemic process brings about death anxiety in people. In pandemic cases, serious concerns such as fear of death and feelings of loneliness arise in patients. Timely mental healthcare for the 2019 novel coronavirus outbreak is urgently needed. The effect of the thought of death on human life is undeniable (Xiang et al., 2020).

Determining the spiritual care requirements and death anxiety levels of individuals diagnosed with COVID-19 in the pandemic period is highly important in terms of increasing the quality of life of these people. To be able to eliminate 
the increasing concerns due to the uncertainty of the pandemic process, it is firstly needed to reveal necessities. However, there is no study in the literature which examined the necessities of individuals diagnosed with COVID-19. Therefore, our study was conducted with the purpose of determining the spiritual care requirements and death anxiety levels of patients diagnosed with COVID-19 in Turkey.

\section{Methods}

\section{Material and Method of the Study}

This study was conducted with the purpose of determining the spiritual care requirements and death anxiety levels of individuals diagnosed with COVID-19.

\section{Population and Sample}

This study was carried out with patients who were diagnosed with COVID-19 in the hospitals of Turkey between the dates of August and September 2020. The sample was determined using the OpenEpi software. In the calculation of the sample, 384 patients were reached with a power of $95 \%$ (Fig. 1).

\section{Sample Size for Frequency in a Population}

$\begin{array}{lc}\text { Population size (for finite population correction factor or fpc) }(N): & 244392 \\ \text { Hypothesized } \% \text { frequency of outcome factor in the population }(p): 50 \%+/-5 \\ \text { Confidence limits as \% of 100(absolute }+/-\%)(d) \text { : } \\ \text { Design effect (for cluster surveys-DEFF): }\end{array}$

Sample Size $(n)$ for Various Confidence Levels

\begin{tabular}{cc}
\hline ConfidenceLevel(\%) & Sample Size \\
$95 \%$ & 384 \\
$80 \%$ & 165 \\
$90 \%$ & 271 \\
$97 \%$ & 471 \\
$99 \%$ & 662 \\
$99.9 \%$ & 1078 \\
$99.99 \%$ & 1505 \\
\hline
\end{tabular}

Equation

Sample size $n=[\mathrm{DEFF} * \mathbf{N p}(\mathbf{1}-\mathrm{p})] /\left[\left(\mathrm{d}^{2} / \mathbf{Z}^{2}{ }_{1-\alpha / 2} *(\mathbf{N}-\mathbf{1})+\mathrm{p} *(\mathbf{1}-\mathrm{p})\right]\right.$

Results from OpenEpi, Version 3, open source calculator--SSPropor

Print from the browser with ctrl-P

or select text to copy and paste to other programs.

Fig. 1 Sample size 


\section{Data Collection Instruments}

The data of the study were collected using a Personal Data Form, the Spiritual Care Requirements Scale and the visual analog scale (VAS) for Death Anxiety.

\section{Personal Data Form}

The Personal Data Form consisted of questions on the sociodemographic data of the patients such as age, sex, marital status, chronic disease status and hospitalization status.

\section{Spiritual Care Requirements Scal}

The scale which was tested for validity and reliability in Turkish by İsmailoğlu et al. (2019) consists of 21 items. The items in the scale are designed to reflect the potential spiritual care needs of patients. Participants are asked to assess their spiritual care needs in each item with a 5-point Likert-type scoring scheme. The assessment is made as, $1=$ "Not necessary at all," $2=$ =Not necessary," 3 ="Does not matter," 4="Necessary" and 5= "Absolutely necessary." Higher scores in the scale indicate higher levels of the spiritual care needs of individuals. The minimum and maximum scores that can be obtained from the scale are 21 and 105. The scale has two factors as "understanding and hope" and "caring and respect." The understanding and hope component involves expressions of mental wellbeing toward the self, nature and environmental factors, while the caring and respect component includes expressions toward relationships with other individuals (Günay et al., 2019).

\section{Visual Analog Scale (VAS) for Death Anxiety}

The visual analog scale (VAS) is used to convert some values that cannot be numerically measured into a numerical measurement. The two extreme definitions of the parameter to be assessed are written on the two ends of a 100-mm line, and individuals are asked to rate their status by marking or showing a point on this line (Williams et al., 2010). In our study, the patients were asked to rate their death anxiety levels in the period where they were diagnosed with COVID-19 on VAS (Fig. 2).

\section{Data Collection}

The questionnaire form was created on the Google Forms system. The questionnaire was sent to patients who were diagnosed with COVID-19 in the hospitals of Turkey on the online environment. Only those volunteering to participate were included in the

Fig. 2 Visual analog scale (VAS) for death anxiety

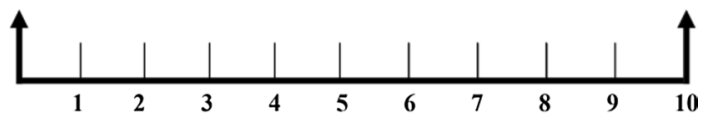


study. The questions of the participants were answered by the researchers. The participants' data were anonymized.

\section{Data Analysis}

The analysis of the data obtained in the study was carried out with the SPSS (Statistical Package for the Social Sciences) 21.0 package software. Numerical and percentage distributions were used in the analysis. Mann Whitney $U$ test was used in the comparisons of independent groups. The level of statistical significance was determined as $p<0.05$.

\section{Research Ethics}

For our study, approval was received from the Scientific Research and Publication Ethics Board of Cappadocia University (29533901-204.01.07-14862), and permission was received from the Platform for Scientific Research on COVID-19 of the Turkish Ministry of Health (2020-09-03T13_37_48).

The patients included in the study were informed about the research, and their consent was obtained online.

\section{Results}

Among the participants included in the study, 63\% $(n=242)$ were female, $41.7 \%$ $(n=160)$ were at the ages of $18-28$, and $62.5 \%(n=240)$ were single. Among the patients, $53.9 \%(n=207)$ did not have a chronic disease, while 55.2\% $(n=212)$ were hospitalized after being diagnosed with COVID-19 (Table 1).

The mean total spiritual care requirements scale (SCRS) score of the participants was $67.05 \pm 26.30$. While their minimum score was 21 , their maximum score was

Table 1 Demographic characteristics of the participants

\begin{tabular}{lll}
\hline Sex & $n$ & $\%$ \\
Female & 242 & 63.0 \\
Male & 142 & 37.0 \\
Age & & \\
$18-28$ & 41.7 & 160 \\
$29-39$ & 17.4 & 67 \\
$40-50$ & 18.8 & 72 \\
51 years or older & 22.2 & 85 \\
Marital status & & \\
Married & 144 & 37.5 \\
Single & 240 & 62.5 \\
Status of chronic disease & & \\
Yes & 177 & 46.1 \\
No & 207 & 53.9 \\
\hline
\end{tabular}


Table 2 Mean total and dimension scores in the spiritual care requirements scale (SCRS)

\begin{tabular}{lll}
\hline Scale total and dimensions & $X \pm \mathrm{SD}$ & Min-Max \\
\hline Understanding and hope & $40.8 \pm 17.25$ & $13-55$ \\
Caring and respect & $26.17 \pm 10.26$ & $8-40$ \\
SCRS total & $67.05 \pm 26.30$ & $21-95$ \\
\hline
\end{tabular}

\begin{tabular}{lll}
\hline & $X \pm$ SD & Min-Max \\
\hline Scale Total Score & $8.82 \pm 1.26$ & $6-10$ \\
\hline
\end{tabular}

Table 3 Mean total score of the participants in VAS for death anxiety

95. The mean subscale scores in the scale were $40.8 \pm 17.25$ in the understanding and hope dimension and $26.17 \pm 10.26$ in the caring and respect dimension (Table 2).

The mean total score of the participants in VAS for Death Anxiety was $8.82 \pm 1.26$. The minimum and maximum scores of the participants were 6 and 10 (Table 3).

In the comparison of the Spiritual Care Requirements Scale mean scores of the participants based on the independent variables, it was found that the difference in the Spiritual Care Requirements Scale total and dimension mean scores based on sex was significant, where the Spiritual Care Requirements Scale total $(U=12,606.50)$, understanding and hope dimension $(U=10,747.50)$ and caring and respect dimension $(U=9445.50)$ mean scores of the male participants were higher $(p<0.05)$. The difference in the Spiritual Care Requirements Scale total and caring and respect dimension scores of the participants based on their status of having a chronic disease was not significant $(p>0.05)$, whereas this difference in the understanding and hope dimension was significant, and those that had a chronic disease had a higher understanding and hope mean score $(U=16,057.50)(p<0.05)$. There was no significant relationship between the participants' status of hospitalization and their Spiritual Care Requirements Scale total and dimension mean scores $(p>0.05)$ (Table 4).

When the participants' mean scores in VAS for Death Anxiety were compared based on the independent variables, it was determined that there was a relationship between their statuses of hospitalization and their mean VAS for Death Anxiety scores, where the mean score of those who were hospitalized was higher $(U=11,688.00)$. There was also a difference between the participants' statuses of having a chronic disease and their mean VAS for Death Anxiety scores, where the mean score of those who had a chronic disease was higher $(U=6614.00)$ (Table 5).

\section{Discussion}

Since the beginning of life, spiritual care has been at the center of situations like healing, quality of life and well-being in both healthy and ill individuals (Koenig, 2012; Roman et al., 2020). This is because spirituality has a strong effect on the 
Table 4 Spiritual Care Requirements Scale Total and Dimension Mean Scores Based on the Independent Variables

Spiritual care requirements scale dimensions

Understanding and hope

$(X \pm \mathrm{SD})$

Sex

Female $(n=242)$

Male $(n=142)$

$$
\begin{aligned}
& 36.15 \pm 17.01 \\
& 48.92 \pm 14.49 \\
& U=10,747.50 \\
& p=0.00^{*}
\end{aligned}
$$

Chronic disease

Yes $(n=177)$

No $(n=207)$

\section{Hospitalization}

Yes $(n=172)$

$43.60 \pm 17.54$

$38.55 \pm 16.69$

$U=16,057.50$

$p=0.036$ *

No $(n=212)$

$$
\begin{aligned}
& 41.70 \pm 19.37 \\
& 39.86 \pm 14.22 \\
& U=16,897.00 \\
& p=0.215
\end{aligned}
$$

Caring and respect $(X \pm \mathrm{SD})$
Spiritual care requirements scale total

Total scale $(X \pm \mathrm{SD})$

$U$ : Mann-Whitney $U,{ }^{*} p<0.05$

Table 5 VAS for death anxiety mean scores based on the independent variables

\begin{tabular}{ll}
\hline VAS for death anxiety & \\
\hline & $\begin{array}{l}\text { VAS for } \\
\text { death anxiety } \\
(X \pm \mathrm{SD})\end{array}$ \\
\hline Hospitalization & \\
Yes $(n=172)$ & $9.16 \pm 0.07$ \\
No $(n=212)$ & $8.41 \pm 0.10$ \\
& $U=11,688.00$ \\
Chronic disease & $p=0.00^{*}$ \\
Yes $(n=177)$ & \\
No $(n=207)$ & $9.60 \pm 0.49$ \\
& $8.19 \pm 1.34$ \\
& $U=6614.00$ \\
& $p=0.00^{*}$ \\
\hline
\end{tabular}

$U$ : Mann-Whitney $U,{ }^{*} p<0.05$

death anxiety
$59.28 \pm 26.70$

$80.28 \pm 19.52$

$U=12,606.50$

$p=0.00^{*}$

$70.25 \pm 27.16$

$64.31 \pm 25.29$

$U=17,487.00$

$p=0.437$

$66.82 \pm 28.58$

$67.33 \pm 23.26$

$U=18,065.00$

$p=0.876$

$\begin{array}{ll}25.11 \pm 10.28 & 66.82 \pm 28.58 \\ 27.41 \pm 10.12 & 67.33 \pm 23.26 \\ U=16,301.00 & U=18,065.00 \\ p=0.073 & p=0.876\end{array}$


beliefs, attitudes, emotions and behaviors of a person (Olson et al., 2015). Being able to use this effect in a positive direction and improving both the physical and mental statuses of patients may be possible by providing spiritual care in a quality manner (Salins et al., 2020).

In our study conducted in the COVID-19 pandemic period, the findings are discussed in the framework of (a) Death anxiety and related factors, (b) Spiritual care requirements and related factors.

Fear or anxiety of death is among the most basic problems experienced by people in pandemic periods (Gasset, 1995). The fast spread of COVID-19 in the global sense and the increase in the COVID-19-related deaths have become a factor that increases anxiety of death among patients diagnosed with COVID-19, as well as increased spiritual care needs (Ferrell et al., 2020). It was reported that the fear as a result of announcements of existing patient numbers, mortality rates and quarantine decisions in the pandemic period increases anxiety (Özyürek \& Atalay, 2020). There are studies showing that the anxiety levels of patients in the COVID-19 pandemic period are high (Zhou et al., 2020). In our study, the mean VAS for Death Anxiety score of the participants was $8.82 \pm 1.26$. This result showed that the death anxiety levels of the patients diagnosed with COVID-19 were high.

Sex is an important variable that genetically, biologically and hormonally leads to differences in the emotions, thoughts and behaviors of individuals. When the VAS for Death Anxiety scores were compared based on sex, it was found that there was a relationship between the mean scores and sex $(p<0.05)$, and the mean VAS for Death Anxiety score of the male participants was higher $(U=11,844.000)$. Similarly, there are also studies in the literature which reported higher death anxiety rates among men (Kurtulan \& Karairmak, 2016; Özyürek \& Atalay, 2020). Seeing this difference in death anxiety based on sex may have been caused by the roles and responsibilities taken on by men and women. We think that, in the pandemic process, while women were spending time with in-house issues by dealing more with household chores and children, and men were more involved in current affairs, they dealt less with in-house issues and experienced concerns about the future of their families may have increased the anxiety levels of the men.

Another variable that affects death anxiety is receiving treatment by staying at the hospital. For patients, hospitalization is always a phenomenon that increases anxiety and stress (Dağlı et al., 2020). Hospitalization requires individuals to leave their familiar environment and enter a strange environment that they do not know (Şentürk, 2020). Additionally, the unknowns about the disease and treatment of the individual increase their anxiety. There are studies reporting that anxiety levels are high among COVID-19 patients receiving treatment as inpatients (Drummond \& Carey, 2020; Kong et al., 2020). In our study, it was determined that the relationship between the participants' hospitalization statuses and their mean VAS for Death Anxiety scores was statistically significant, and those who were hospitalized had a higher mean score $(U=11,688.00)$. It is possible to state that this significant difference was caused by that COVID-19 patients might not be treated at home, they may need treatment under hospital conditions or intensive care conditions, such patients are isolated, the disease may be deadly, there are damages in some parts of the body related to the disease, and the patients experience anxiety due to these reasons. 
Chronic diseases are slowly processing diseases that are seen for three months or longer, caused by multiple risk factors and affect the quality of life of the individual negatively (Sandalc1 et al., 2020). Chronic diseases are at the top of the risk factors that increase the fatality rates in the COVID-19 pandemic worldwide (Organization, 2020). The existing chronic diseases of patients diagnosed with COVID-19 make the clinical picture more severe and lead to mortality (Sofulu et al., 2020). A study conducted with patients diagnosed with COVID-19 determined that $23.7 \%$ of the participants had at least one comorbid chronic disease (hypertension, diabetes, chronic obstructive pulmonary disease) (Guan et al., 2020). In another study, chronic diseases were determined in $51 \%$ of patients diagnosed with COVID-19, while most of these diseases were cardiovascular diseases, cerebrovascular diseases and diabetes (Chen et al., 2020). In our study, it was determined that the participants' chronic disease statuses and their mean VAS for Death Anxiety scores were significantly related, and those that had chronic diseases had a higher mean score $(U=6614.00)$. Based on this result, we think that chronic diseases are a situation that creates death anxiety in people as many patients diagnosed with COVID-19 have accompanying chronic diseases.

Spirituality, meaning connection to spiritual-ethereal values, expresses the effort of the individual to understand life and death and includes the gains obtained by the individual throughout life in making sense of their place in the universe (Kaplan \& Arkan, 2020). For overcoming and managing problems in their lives, individuals utilize their personal experiences, as well as moral, spiritual and cultural values (Hiçdurmaz \& Oz, 2013). Therefore, the spiritual aspect of the person is considered as important as their physical, social and emotional aspects, and these aspects are in an interaction with each other. For this reason, spiritual care is in the position of support which allows the individual to effectively fight against crisis situations (Kökçü \& Kutlu, 2020). In our study, the mean score of the participants in the Spiritual Care Requirements Scale was $67.05 \pm 26.30$. This score suggested that the patients required spiritual care in the period they were diagnosed with COVID-19. In the literature, it has been reported that the need for spiritual care increased in patients with chronic disease, those receiving cancer treatment and those with a disease that has a poor prognosis (Anisa et al., 2018; Kökçü \& Kutlu, 2020). This result of our study may have been caused by that there had been no assistive intervention or practice toward the spiritual care needs of the patients, and the necessary importance was not paid to spiritual care.

It is known in the literature that the spiritual care needs of patients with chronic diseases are higher in comparison to other patients (Balboni et al., 2007; Y1ldırım et al., 2013). In the study on spiritual care needs by Hsiao et al. (2011), 88\% of patients with chronic diseases stated that having hope is important for survival. In another study, Kılınç et al. (2016) reported that level of hope affected stress, physical activity and spirituality in patients with chronic diseases. In our study, in support of the literature, it was found that the relationship between the chronic disease status of the patients diagnosed with COVID-19 and their spiritual care requirement understanding and hope dimension scores was significant, and those that had a chronic disease had a higher mean score in the understanding and hope dimension $(U=16,057.50)(p<0.05)$. This situation, with their chronic diseases, may have caused the patients to feel inadequate and dependent and increased their spiritual care needs, as it made it a requirement to have lifestyle changes in aspects like physical activity, nutrition and communication due to COVID-19. 


\section{Limitations and Strengths of the Study}

The limitation of this study is that individuals with limited use of technology could not be reached due to the fact that the research was conducted over the Internet, and it is not known whether the people with whom the participants live together are infected with the virus. On the other hand, the online collection of the data, and thus, the inclusion of participants from different hospitals and the large sample size were the strengths of the study.

\section{Conclusion}

Our study was conducted with the purpose of determining the spiritual care requirements and death anxiety levels of individuals diagnosed with COVID-19. In our study, the death anxiety levels of the patients diagnosed with COVID-19 were high. The mean score of the participants in the Spiritual Care Requirements Scale was high. This result suggested that the patients required spiritual care in the period they were diagnosed with COVID-19. Therefore, it is very important to determine the death anxiety levels and spiritual needs of patients diagnosed with COVID.

Authors contributions Study conception and design: Seda ŞAHAN; Data collection: Seda ŞAHAN, Ayşegül YILDIZ; Data analysis and interpretation: Seda ŞAHAN, Ayşegül YILDIZ; Drafting of the article: Seda ŞAHAN, Ayşegül YILDIZ.

\section{Declarations}

Conflict of interest The authors declare that they have no conflict of interest.

Availability of data and material Yes.

\section{References}

Adhikari, S. P., Meng, S., Wu, Y.-J., Mao, Y.-P., Ye, R.-X., Wang, Q.-Z., Sun, C., Sylvia, S., Rozelle, S., \& Raat, H. (2020). Epidemiology, causes, clinical manifestation and diagnosis, prevention and control of coronavirus disease (COVID-19) during the early outbreak period: A scoping review. Infectious Diseases of Poverty, 9(1), 1-12. https://doi.org/10.1186/s40249-020-00646-X

Anisa, N. R., Erika, K. A., \& Rachmawaty, R. (2018). Nurse's spiritual care competencies to patient with end stage breast cancer. International Journal of Public Health, 7(4), 268-273. https://doi.org/10. 11591/ijphs.v7i4.14742

Arslan, H., \& Konuk Şener, D. (2009). Examining the concepts of stigma, spirituality and comfort according to the concept development process of Meleis. Maltepe University Journal of Nursing Science and Art, 2(1), 51-58.

Balboni, T. A., Vanderwerker, L. C., Block, S. D., Paulk, M. E., Lathan, C. S., Peteet, J. R., \& Prigerson, H. G. (2007). Religiousness and spiritual support among advanced cancer patients and associations with end-of-life treatment preferences and quality of life. Journal of Clinical Oncology: Official Journal of the American Society of Clinical Oncology, 25(5), 555.

Benito, E., Oliver, A., Galiana, L., Barreto, P., Pascual, A., Gomis, C., \& Barbero, J. (2014). Development and validation of a new tool for the assessment and spiritual care of palliative care patients. 
Journal of Pain Symptom Management, 47(6), 1008-1018. e1001. https://doi.org/10.1016/j.jpain symman.2013.06.018

Brennan, F. (2013). Holistic Palliative Care approach-physical, spiritual, religious and psychological needs. Nephrology Nursing Journal. https://doi.org/10.1111/nep.12076

Chen, N., Zhou, M., Dong, X., Qu, J., Gong, F., Han, Y., Qiu, Y., Wang, J., Liu, Y., \& Wei, Y. (2020). Epidemiological and clinical characteristics of 99 cases of 2019 novel coronavirus pneumonia in Wuhan, China: A descriptive study. The Lancet, 395(10223), 507-513. https://doi.org/10.1016/ S0140-6736(20)30211-7

Como, J. M. (2007). Spiritual practice: A literature review related to spiritual health and health outcomes. Holistic Nursing Practice, 21(5), 224-236. https://doi.org/10.1097/01.HNP.0000287986. 17344.02

Çetinkaya, B., Altundağ, S., \& Azak, A. (2007). Spiritual care and nursing. Journal of Adnan Menderes University Faculty of Medicine, 47-50.

Çınar, F., \& Eti Aslan, F. (2017). Spiritualism and nursing: The importance of spiritual care in intensive care patients. Journal of Academic Research in Nursing, 3(1), 37-42. https://doi.org/10. 5222/jaren.2017.037

Dağlı, D. A., Büyükbayram, A., \& Arabac1, L. B. (2020). Psychosocial approach to the patient and family diagnosed with COVID-19. Journal of Izmir Katip Celebi University Faculty of Health Sciences, 5(2), 191-195.

Deal, B., \& Grassley, J. S. (2012). The lived experience of giving spiritual care: A phenomenological study of nephrology nurses working in acute and chronic hemodialysis settings. Nephrology Nursing Journal, 39(6).

Drummond, D. A., \& Carey, L. B. (2020). Chaplaincy and spiritual care response to COVID-19: An Australian case study-The McKellar Centre. Health Social Care Chaplaincy. https://doi.org/10. 1558/hscc.41243

Elham, H., Hazrati, M., Momennasab, M., \& Sareh, K. (2015). The effect of need-based spiritual/religious intervention on spiritual well-being and anxiety of elderly people. Holistic Nursing Practice, 29(3), 136-143. https://doi.org/10.1097/HNP.0000000000000083

Ferrell, B. R., Handzo, G., Picchi, T., Puchalski, C., \& Rosa, W. E. (2020). The urgency of spiritual care: COVID-19 and the critical need for whole-person palliation. Journal of Pain Symptom Management, 60(3), e7-e11. https://doi.org/10.1016/j.jpainsymman.2020.06.034

Gasset, O. (1995). Human and everyone. Detail publications.

Guan, W.-J., Ni, Z.-Y., Hu, Y., Liang, W.-H., Ou, C.-Q., He, J.-X., Liu, L., Shan, H., Lei, C.-L., \& Hui, D. S. (2020). Clinical characteristics of coronavirus disease 2019 in China. New England Journal of Medicine, 382(18), 1708-1720.

Günay, İE., Özdemir, H., Ahmet, E., \& Zaybak, A. (2019). The validity and reliability of the Turkish form of the spiritual care needs scale. Dokuz Eylul University Faculty of Nursing Electronic Journal, 12(4), 255-263.

Heidari, M., Heidari, A., \& Yoosefee, S. (2020). COVID-19 pandemic and the necessity of spiritual care. Iranian Journal of Psychiatry, 15(3), 262-263.

Hiçdurmaz, D., \& Oz, F. (2013). Spirituality as a dimension of coping with stress. Anatolian Journal of Nursing and Health Sciences, 16(1), 50-56.

Hsiao, S. M., Gau, M. L., Ingleton, C., Ryan, T., \& Shih, F. J. (2011). An exploration of spiritual needs of Taiwanese patients with advanced cancer during the therapeutic processes. Journal of Clinical Nursing, 20(7-8), 950-959. https://doi.org/10.1111/j.1365-2702.2010.03278.x

İsmailoğlu, E. G., Özdemir, H., Ahmet, E., \& Zaybak, A. (2019). The validity and reliability of the Turkish version of the spiritual care needs scale. Dokuz. Eylul University Faculty of Nursing Electronic Journal, 12(4), 255-263.

Kaplan, F., \& Arkan, B. (2020). Spirituality and Nursing Academic Studies in Health Sciences-II, 220-241.

Kılınç, G., Yıldız, E., \& Kavak, F. (2016). The relationship between healthy lifestyle behaviors and hopelessness in heart failure patients. Journal of Cardiovascular Nursing, 7(13), 114-126.

Koenig, H. (2012). Religion, spirituality, and health: The research and clinical implications. ISRN Psychiatry, 2012.

Kong, X., Zheng, K., Tang, M., Kong, F., Zhou, J., Diao, L., Wu, S., Jiao, P., Su, T., \& Dong, Y. (2020). Prevalence and factors associated with depression and anxiety of hospitalized patients with COVID19. MedRxiv. https://doi.org/10.1101/2020.03.24.20043075 
Kökçü, Ö. D., \& Kutlu, Ö. (2020). Spiritual care in cardiovascular system diseases. Ege University Faculty of Nursing Journali, 36(1), 53-59.

Kurtulan, M. H., \& Karairmak, Ö. (2016). Examination of the relationships between death anxiety, spirituality, religiosity and existential anxiety. Spiritual Psychology Counseling, 1-2.

Lundberg, P. C., \& Kerdonfag, P. (2010). Spiritual care provided by Thai nurses in intensive care units. Journal of Clinical Nursing, 19(7-8), 1121-1128. https://doi.org/10.1111/j.1365-2702.2009. 03072.x

Mahase, E. (2020). China coronavirus: WHO declares international emergency as death toll exceeds 200. BMJ: British Medical Journal, 368. https://doi.org/10.1136/bmj.m408

Olson, J., Brémault-Phillips, S., Sinclair, S., Parmar, J., Weis, J., Abbasi, M., Puchalski, C. M., Magnus, R., Brett-MacLean, P., \& Oneschuk, D. (2015). Integrating spirituality as a key component of patient care. Religions, 476-498.

Organization, W. H. (2020). Noncommunicable diseases Retrieved May 3, 2020, from https://www.who. $\mathrm{int/news-room/fact-sheets/detail/}$

Özyürek, A., \& Atalay, D. (2020). Investigation of the relationship between meaning of life and death anxiety and well-being in adults in the Covid-19 pandemic. TURAN: Center for Strategic Studies, 12(46), 458-472.

Roman, N. V., Mthembu, T. G., Hoosen, M., \& Medicine, F. (2020). Spiritual care-'A deeper immunity'-A response to Covid-19 pandemic. African Journal of Primary Health Care, 12(1). https://doi. org/10.4102/phcfm.v12i1.2456

Salins, N., Mani, R. K., Gursahani, R., Simha, S., \& Bhatnagar, S. (2020). Symptom management and supportive care of serious COVID-19 patients and their families in India. Indian Journal of Critical Care Medicine: Peer-Reviewed, Official Publication of Indian Society of Critical Care Medicine, 24(6), 435. https://doi.org/10.5005/jp-journals-10071-23400

Sandalc1, B., Uyaroğlu, O. A., \& Güven, G. S. (2020). The role, importance and recommendations of chronic diseases in COVID-19. Flora Journal, 25(5).

Seddigh, R., Keshavarz-Akhlaghi, A.-A., \& Azarnik, S. (2016). Questionnaires measuring patients' spiritual needs: A narrative literature review. Iranian journal of psychiatry behavioral sciences, 10(1). https://doi.org/10.17795/ijpbs-4011

Selman, L., Harding, R., Gysels, M., Speck, P., \& Higginson, I. (2011). The measurement of spirituality in palliative care and the content of tools validated cross-culturally: A systematic review. Journal of Pain Symptom Management, 41(4), 728-753. https://doi.org/10.1016/j.jpainsymman.2010.06.023

Sofulu, F., Uran, B. Ö., Avdal, E. Ü., \& Tokem, Y. (2020). Nursing management in chronic diseases in the COVID-19 outbreak. Journal of Izmir Katip Celebi University Faculty of Health Sciences, 5(2), 147-151.

Şentürk, H. (2020). A pilot study on the need for spiritual counseling services in hospitals: The case of SDU hospital. ODU Journal of Social Sciences Research, 10(2), 373-396.

Tiew, L. H., Creedy, D. K., \& Chan, M. F. (2013). Student nurses' perspectives of spirituality and spiritual care. Nurse Education Today, 33(6), 574-579. https://doi.org/10.1016/j.nedt.2012.06.007

Williams, V. S., Morlock, R. J., \& Feltner, D. (2010). Psychometric evaluation of a visual analog scale for the assessment of anxiety. Health and Quality of Life Outcomes, 8(1), 1-8.

WHO COVID-2019 situation reports 209. https://www.who.int/emergencies/diseases/novel-coronavirus2019/situation-reports. Accessed 1 September 2020.

Xiang, Y.-T., Yang, Y., Li, W., Zhang, L., Zhang, Q., Cheung, T., \& Ng, C. H. (2020). Timely mental health care for the 2019 novel coronavirus outbreak is urgently needed. The Lancet Psychiatry, 7(3), 228-229. https://doi.org/10.1016/S2215-0366(20)30046-8

Yıldırım, N. K., Kaçmaz, N., \& Özkan, M. (2013). Unmet care needs of advanced cancer patients. Journal of Psychiatric Nursing, 4(3), 153-158.

Zhou, J., Liu, L., Xue, P., Yang, X., \& Tang, X. (2020). Mental health response to the COVID-19 outbreak in China. American Journal of Psychiatry. https://doi.org/10.1176/appi.ajp.2020.20030304

Publisher's Note Springer Nature remains neutral with regard to jurisdictional claims in published maps and institutional affiliations. 